\title{
Cross-Cultural Variation in the Use of Hedges and Boosters in Academic Discourse
}

\section{Olga Dontcheva-Navratilova}

Hedges and boosters are important metadiscoursal devices contributing to the construal of persuasion in academic discourse as they enable academic writers to distinguish facts from opinions, evaluate the views of others and convey a different degree of commitment to their assertions (cf. Hyland 19g8a, Hyland 2004, 2005). This study explores cross-cultural variation in the use of lexical hedges and boosters in the academic discourse of non-native writers. The study is carried out on a specialized corpus of linguistics research articles published in the international journal Applied Linguistics and the national Czech English-medium journal Discourse and Interaction. The main purpose of the cross-cultural investigation is to analyze variation in the rate, distribution and choice of hedges and boosters across the rhetorical structure of research articles in order to shed light on ways in which Anglophone and Czech writers express different degrees of commitment in their assertions when striving to persuade their target readership to accept their views and claims.

\section{Keywords}

Boosters; hedges; metadiscourse; research article; cross-cultural variation

\section{Introduction}

The hegemony of English as the lingua franca of the modern academic world has forced scholars from non-Anglophone linguacultural backgrounds to publish in English in order to get access to disciplinary networks and become an integral part of globalized academia. This has called for intensive research into their English-medium written discourse with the aim of establishing whether and to what extent they accommodate to the prevailing rhetoric when striving to persuade their readers of the relevance, validity and novelty of their claims and views. Many recent cross-cultural studies in this area have focused on different aspects of the interpersonal dimension of academic interaction, such as authorial presence (e.g., Vassileva 1998, 2000, Fløttum 
2003, Yakhontova 2006, Mur-Duňas 2007, Molino 2010, DontchevaNavratilova 2013a), citation practices (e.g., Mur-Duňas 2009, Hewings, Lillis and Vladimirou 2010, Dontcheva-Navratilova 2015b), hedges and boosters (e.g., Vázquez and Giner 2008, 2009, Martín-Martín 2008, Ku and Cao 2011, Yang 2013, Abdollahzadeh 2011, Samaie, Khosravian Boghayeri 2014) and clusters of metadiscoursal features (Mauranen 1993, Vassileva 2000, 2001, Povolná 2012, Dontcheva-Navratilova 2015). The findings of these studies have indicated that the rhetorical strategies used by academic writers are affected by their socio-cultural background and the expectations of their intended readership, and they have pointed out the need for further research into variation in academic discourse along the linguacultural axis.

This study explores cross-cultural variation in the use of hedges and boosters as metadiscourse devices in research articles by Anglophone and Czech linguists published in the international journal Applied Linguistics and the national English-medium Czech journal Discourse and Interaction. Rooted in a conceptualization of academic writing as social engagement (Hyland and Tse 2004: 156), metadiscourse is seen as comprising "the self-reflective expressions used to negotiate interactional meanings in a text, assisting the writer (or speaker) to express a viewpoint and engage with readers as members of a particular community" (Hyland 2005: 37). Metadiscourse markers can be grouped into two categories according to their prevailing function in writer-reader interaction: (1) interactive metadiscourse devices, which have a discourse organizing function and guide the reader through the text, and (2) interactional metadiscourse devices, which have an evaluative function and convey the writer's attitude towards the knowledge conveyed, while engaging in a dialogue with the intended reader (Hyland 2004: 158). Hedges and boosters pertain to interactional metadiscoursal devices. They convey the writer's degree of confidence in the truth of the proposition and express an attitude towards the audience (Hyland 2004: 87). The use of hedges enables academic writers to acknowledge the existence of alternative voices and viewpoints and to withdraw their full commitment to the proposition, while the use of boosters helps them to close down alternatives and to show a high degree of certainty (Hyland 2005: 52).

The way in which writers use hedges and boosters, and metadiscourse as such, is likely to be affected by several factors comprising the social and cultural background of the writer, the epistemological and literacy tradition he/she is associated with, and the genre and disciplinary conventions (DontchevaNavratilova 2013, Ivanić 1998). A brief comparison of the Anglophone and 
Czech linguistics discourse communities and academic literacies identifies some features that may affect the way in which their members present and evaluate disciplinary knowledge and communicate with their readership. Previous comparative research (e.g., Čmejrková 1994, Čmejrková \& Daneš 1997, Chamonikolasová 2005, Povolná 2012, 2015, Dontcheva-Navratilova 2013a,b, 2015) has shown that these traditions differ considerably in the way they approach writer-reader interaction. An important difference stems from the size of the two linguistics discourse communities. While the Anglophone academic community is large, culturally heterogeneous and highly competitive, the Czech community is small, culturally rather homogeneous, epistemologically less diversified and tends towards avoidance of tension. As a result, when addressing their highly diverse depersonalized readership, Anglophone writers seem to invest a considerable persuasive effort, associated with marked reader awareness and explicit discourse organization. Czech linguists, in contrast, interact with their readers by claiming a reliance on shared research interests and methodology and typically opt for a less structured discourse marked by a lower level of interactiveness and backgrounded authorial presence (Čmejrková \& Daneš 1997, Chamonikolasová 2005). However, as recent research has shown (Dontcheva-Navratilova 2013a,b, 2015), the academic discourse of Czech linguists, especially in their English-medium publications, is changing under the influence of globalization and pressure exerted by Anglophone academic discourse, thus giving rise to "hybridizing forms" which reflect tension derived from intercultural clashes (Gotti 2012).

The aim of this investigation is to explore how Anglophone and Czech linguists approach writer-reader interaction through the use of hedges and boosters in their English-medium texts. The contrastive analysis focuses on the rate, distribution and choice of hedges and boosters across the rhetorical structure of research articles. The study endeavours to explain the reasons for the existing divergences in the ways Anglophone and Czech writers express different degrees of commitment to their assertions when striving to persuade their intended readership to accept their views and claims.

\section{Hedges and boosters in academic discourse}

Hedges and boosters are key interactional devices used by writers of research articles to negotiate their credibility, modify the truth-value of the knowledge conveyed, and show different degrees of commitment to opinions and claims 
when they engage in a dialogue with the reader (Salager-Meyer 1994, Hyland 2005). They can be seen as realizations of the communicative strategies of hedging and boosting aimed at persuading the reader to agree with the knowledge claims and opinions expressed by the speaker, while showing solidarity with and collegial respect for members of the disciplinary discourse community (Hyland 1998, 2000). Hedges, defined by Lakoff (1973: 195) as expressions that "make things fuzzier or less fuzzy", express epistemic modality meanings aimed at reducing commitment to claims; they also acknowledge alternative viewpoints (Hyland 2005), mitigate the force of an utterance and may be seen to abide by negative politeness considerations (Holmes 1990, Brown \& Levinson 1987). Boosters enhance the illocutionary force of speech acts (Holmes 1984), emphasize certainty and strengthen commitment to claims and views (Gillaerts \& Van de Velde 2010, Hyland 1998a). Unlike hedges, boosters are not intrinsically a politeness device, and their contribution to the expression of solidarity depends on their contextual interpretation (Holmes 1995: 77). While hedges have received considerably more attention in previous research, hedges and boosters are regarded here as representing a cline of assertiveness, as when seeking acceptance for their work academic writers need to balance conviction with caution in order to build up "an appropriate disciplinary persona of modesty and assertiveness" (Hyland 2000: 180). The accurate location of instances of hedges and boosters on that cline may be rather problematic, as hedging and boosting are best seen as "polypragmatic" (Hyland 1996: 347) interactional discourse strategies, i.e., the function of hedges and boosters varies depending on the co-text and the communicative situation in which they are used.

There are various approaches to the categorization of hedges and boosters (e.g., Prince et al. 1982, Salager-Meyer 1994, Clemen 1997, Mauranen 1997); they draw on formal, lexico-grammatical, functional criteria or adopt an eclectic approach. This investigation adopts Hyland's (1996, 1998b) taxonomy of hedging devices, which is probably most influential; it accounts for the discourse functions of hedges and can be extended to account for the functions of boosters as well. Within this approach hedges and boosters can be divided into two broad categories, namely content-oriented hedges and boosters, which reflect the accuracy and reliability of the statement as a representation of reality, and participant-oriented hedges and boosters, which concern the interaction between the writer and the audience. The balance of contentand participant-oriented hedges and boosters is a key factor in achieving 
persuasion in research articles, as they modulate the author's account of the reality and his/her relationships with the social community involved in the construction of disciplinary knowledge.

Hedges and boosters can be realized by various lexico-grammatical markers, such as modal verbs (e.g., may, would, must), lexical verbs (e.g., suggest, think, show), adverbs (e.g., possibly, certainly, obviously), adjectives (e.g., probable, potential, evident) and phrases (in fact, in our view), indirect and parenthetical constructions, passives and if-clauses. In addition, Hyland (1996, 1998a) includes some discourse strategies performing hedging and boosting functions, e.g., commenting on difficulties encountered, pointing to shortcomings and alternative explanations can be seen as strategies performing a hedging function, while claiming "consensual understandings based on shared community membership" (Hyland 1998a: 368) may be regarded as a boosting strategy. This study focuses on the frequency of occurrence, functions and distribution of hedges and boosters in the rhetorical structure of research articles and pays only peripheral attention to the categories of lexical items realizing these interactional devices; future research should explore in greater depth whether there is some correlation between the lexico-grammatical categories of hedges and boosters and their functional specialization.

\section{Data and methodology}

This investigation into cross-cultural variation in the use of hedges and boosters is carried out on a specialized corpus consisting of 24 research articles published in the international journal Applied Linguistics (AL) and the Czech national journal Discourse and Interaction (DI) in the period 20012015. The two journals clearly differ in several respects. Applied Linguistics (impact factor 1.453/2014) is a well-established international academic journal published by Oxford University Press since 1980 which addresses the global applied linguistics discourse community. Discourse and Interaction is a more locally oriented national English-medium linguistics journal published by Masaryk University in Brno (Czech Republic) since 2008 whose intended readership is most likely to comprise the Central European linguistics discourse community. Still, the two journals are considered to provide representative samples of research articles produced by members of the Anglophone and Czech academic discourse communities respectively and, therefore they are 
regarded as appropriate and comparable sources of texts for the purposes of the present research. The differences in the intended readership of the journals may be seen as one reason for variation in the metadiscoursal devices used by the writers.

The corpus was compiled so as to ensure comparability in terms of genre (research article), field (linguistics) and composition (number of texts per author/language). Since previous research has evidenced considerable idiosyncratic variation in the use of interactional devices (e.g., Mur-Dueňas 2007, Dontcheva-Navratilova 2013a,b) equal representation of authors was prioritized over equal word-count of the samples (for a similar approach cf. Mur-Dueňas 2007, 2009, Martín-Martín 2008, Molino 2010, Yang 2013). Thus the corpus comprises 12 research articles by Anglophone authors $(89,500$ words), representing the writing habits of 12 native-speaker linguists (judging by their names and affiliations), and 12 by Czech authors (52,000 words), representing the writing habits of 12 Czech linguists using English as an academic lingua franca. In agreement with the common procedure in contrastive corpus-based research, the difference in word-count between the $\mathrm{AL}$ and the DI sub-corpora was neutralized by normalization, i.e., the raw frequencies for each sub-corpus were converted into frequencies per 1,000 words, using the following formula: normalized frequency per 1,00o words $=$ (raw frequency $\div$ text word-count $) \times 1,000$. Obviously, the text sample is rather small (totalling 141,500 words); however, as specialized corpora have been proved to be appropriate for top-down, contextually-informed analyses of academic and professional discourse (Flowerdew L. 2004: 18), I believe that the material yields enough grounds for a cross-cultural analysis of the use of hedges and boosters in research articles by Anglophone and Czech linguists. In addition, several previous cross-cultural studies on interactional devices which yielded relevant results scrutinized small specialized corpora, e.g., Vassileva's (2001) corpus consists of 6o pages of text per language, Mur-Dueñas's (2007, 2009) corpus comprises 24 articles (140,000 words), and Yang's (2013) corpus is made up of 20 research articles (80,000 words).

While there is a plethora of linguistic devices that can function as hedges and boosters, as with numerous previous studies (e.g., Hyland \& Milton 1997, Varttala 1999, Hyland 2000, Vázquez \& Giner 2008, 2009) this study focuses only on epistemic lexical items that can be interpreted as modifying the degree of authorial certainty and confidence, which are regarded as the most frequent realizations of hedges and boosters. Occurrences of hedges and boosters in 
the corpus were identified by drawing on lists suggested by Hyland (2005) and do not take into account the lexicogrammatical category of the lexical items functioning as hedges and boosters. Clusters of hedges or boosters were counted as one occurrence of the respective discourse strategy (e.g., may suggest, clearly show). As stated above, the raw data were then normalized to frequencies per 1,00o words to allow for a comparison of the rate of occurrence of hedges and boosters and their distribution within the rhetorical structure of research articles in the $A L$ and the $D I$ sub-corpora. The examples discussed are intended to illustrate variation in the rhetorical strategies preferred in the Anglophone and Czech linguacultural contexts.

\section{Results and discussion}

The contrastive analysis of the rate, distribution and choice of hedges and boosters in the research articles by Czech and Anglophone linguists aims at identifying and explaining reasons for the existing variation in the use of these metadiscourse devices.

\subsection{Frequency of occurrence of hedges and boosters in the DI and AL sub-corpora}

As the results of a quantitative analysis of occurrence of hedges and boosters in the $D I$ and $A L$ sub-corpora summarized in Table 1 show, there are significant differences in their rate in the two sub-corpora. The frequency of occurrence of hedges and boosters is considerably higher in the $A L$ sub-corpus (13.91 per 1,000 words, 113 per research article) than in the DI corpus (7.84 per 1,000 words, 34 per research article). These results indicate that Anglophone linguists tend to use hedges and boosters more systematically in an effort to rhetorically manipulate readers into accepting their views and claims. Czech linguists, on the other hand, are more likely to opt for a more descriptive, less dialogic style or employ alternative persuasive devices. This variation in culturally preferred rhetorical strategies is generally in consonance with the findings of previous research into interpersonal metadiscourse in Anglophone (e.g., Hyland 1998c, 2008) and Czech (e.g., Čmejrková \& Daneš 1997, Chamonikolasová 2005) academic discourse. 
Table 1 - Hedges and boosters in the DI and AL sub-corpora

\begin{tabular}{|l|l|l|l|l|l|l|l|l|l|}
\hline \multirow{2}{*}{ Corpus } & \multicolumn{2}{|l|}{ Hedges } & \multicolumn{2}{l|}{ Boosters } & \multicolumn{3}{l|}{ Total } \\
\cline { 2 - 10 } & $\begin{array}{l}\text { Raw } \\
\text { No }\end{array}$ & $\begin{array}{l}\text { Per } 1000 \\
\text { words }\end{array}$ & $\begin{array}{l}\text { Per } \\
\text { cent }\end{array}$ & $\begin{array}{l}\text { Raw } \\
\text { No }\end{array}$ & $\begin{array}{l}\text { Per } 1000 \\
\text { words }\end{array}$ & $\begin{array}{l}\text { Per } \\
\text { cent }\end{array}$ & $\begin{array}{l}\text { Raw } \\
\text { No }\end{array}$ & $\begin{array}{l}\text { Per } 1000 \\
\text { words }\end{array}$ & $\begin{array}{l}\text { Per } \\
\text { cent }\end{array}$ \\
\hline RA $\boldsymbol{D I}$ & 260 & 5.00 & $63.7 \%$ & 148 & 2.84 & $36.3 \%$ & 408 & 7.84 & 100 \\
\hline RA $\boldsymbol{A L}$ & 1029 & 11.49 & $80.0 \%$ & 327 & 3.65 & $20.0 \%$ & 1356 & 13.91 & 100 \\
\hline
\end{tabular}

It is significant that the incidence of hedges in the $A L$ sub-corpus (11.49 per 1,000 words, 85.7 per RA) is lower than the frequency of 18.0 per 1,00o words (114 per article) reported by Hyland (1998a: 9) for his applied linguistics subcorpus. The same decreasing tendency is even stronger in the rate of boosters, which occur with a frequency of $3.3^{6}$ per 1 , ooo words (27.6 per RA) in the $A L$ sub-corpus, while Hyland reports a rate of 6.2 per 1,ooo words (39.1 per $\mathrm{RA}$ ). This divergence may stem from the composition of the corpora, variation in the analysts' interpretation of the data, or the approach adopted in this study to count hedge and booster clusters as one occurrence of the respective rhetorical strategy. More importantly, however, the decrease in the rate of hedges and boosters may be interpreted as a diachronic change reflecting different pressures on the discipline and the scholarly ethos over the last two decades. As Gillaerts and Van de Velde (2010: 136) have indicated in their research into metadiscourse markers in research article abstracts, over the last thirty years there seems to have been an overall reduction in the number of interactional metadiscourse devices in (applied) linguistics, which plausibly reflects a "converging move towards the hard sciences", where interactional metadiscourse has been shown to be less prominent (Hyland 2005). The substantial drop in the rate of boosters evidenced by my data may stem from the need to background authorial stance and acknowledge numerous different voices and views within the now globalized academic discourse community. The decrease in the occurrence of hedges, however, is less significant, since they are employed for mitigating opinions and cautious presentation of scientific claims when striving to achieve scholarly credibility. This may be seen as a "shift in rhetorical ethos" (Gillaerts and Van de Velde 2010: 137), i.e., academic "omniscience" is questioned and gives way to a more dialogic and interactive way of building up a credible and persuasive authorial persona.

A closer look at the distribution of hedges and boosters in the $A L$ and $D I$ sub-corpora reveals that there is marked difference in the ways Czech and 
Anglophone linguists approach these rhetorical strategies (Table 1, Figure $1)$.

Figure 1 - Hedges and boosters in the DI and AL sub-corpora

Rate of hedges and boosters in the $D I$ and $A L$ sub-corpora per 1,0oo words

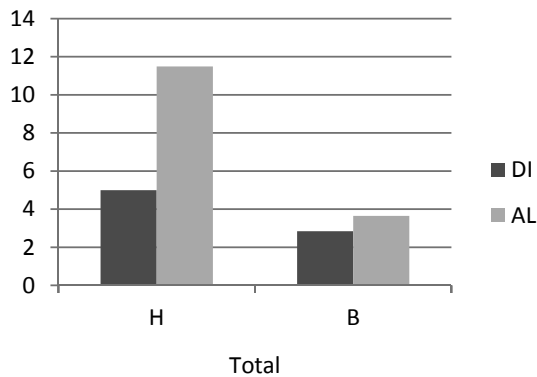

Percentage of occurrence of hedges and boosters in the DI and AL sub-corpora

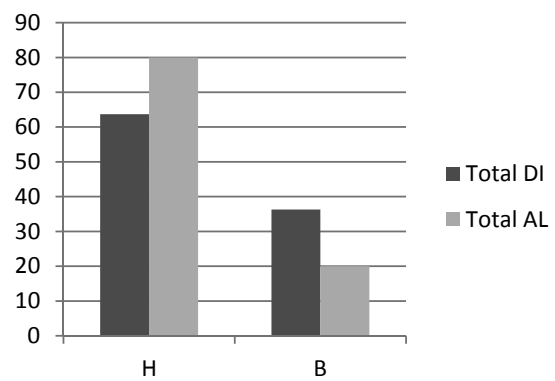

Hedging is more prominent in research articles by Anglophone linguists, as the rate of hedges in the $A L$ sub-corpus is more than double that of the $D I$ sub-corpus (11.49 per 1,000 words in the $A L$ corpus; 5.00 per 1,000 words in the $D I$ corpus); the divergence in the incidence of boosters, however, is considerably less significant (3.65 per 1,000 words in the $A L$ corpus; 2.84 per 1,000 words in the DI corpus). The proportional representation of the two rhetorical strategies also differs in the two sub-corpora: in the $A L$ subcorpus the ratio of hedges to boosters is $4: 1$ (80\% vs. 20\%), while in the DI sub-corpus it is $2: 1(63.7 \%$ vs. $36.3 \%)$. These divergences seem to stem from the linguacultural background of the authors, the size and dynamics of the respective discourse communities and the intended readership.

The rhetorical choices of Anglophone authors may be seen as a reflection of the above-mentioned diachronic change in the use of interactional metadiscourse devices. The globalized heterogeneous audience of the Applied Linguistics journal seems to impose some constraints on the use of boosters as devices for promoting a marked authorial view. At the same time, it is the international readership together with the large size and competitive character of the globalized linguistics discourse community that encourages the use of hedges as an expression of rhetorical efforts aimed at expressing tentativeness 
and cautious commitment to claims and views. On the other hand, the tendency towards symbiosis and avoidance of tension in the small Czech linguistics discourse community and the still high prestige of scholarly "omniscience" allows for an expression of marked authorial stance, which seems to motivate the higher proportion of boosters in the $D I$ sub-corpus. The relatively low ratio of hedges in the $D I$ sub-corpus is somewhat surprising when one takes into consideration that according to Čmejrková and Daneš (1997: 44) Czech academic writing is characterized by a lesser degree of assertiveness, expressed by the use of tentative and qualified language. A plausible explanation for this may be that when writing English-medium text oriented towards an international readership, Czech linguists try to adapt to a different rhetorical style and thus diverge from the rhetorical conventions of Czech academic discourse. This concurs with the findings of recent cross-cultural research (e.g., $\mathrm{Hu} \&$ Cao 2011, Takimoto 2015), which suggest that non-Anglophone authors from different linguacultural backgrounds tend to use more boosters and fewer hedges in their texts than do Anglophone authors in comparable texts, thus expressing a higher degree of authorial certainty. While in the case of novice authors this variation in the use of hedges and boosters may be attributed to a lack of awareness of their role in expressing different degrees of certainty, in the case of expert non-Anglophone linguists the expression of a higher degree of assertiveness may be interpreted as a promotional strategy that the authors use in an effort to accommodate to the competitive settings of globalized academia. These preliminary results, however, cannot be generalized before being corroborated by further larger-scale studies covering a wider range of linguacultural backgrounds.

\subsection{Distribution of hedges and boosters across the rhetorical structure of research articles in the DI and AL sub-corpora}

The results of the analysis of the distribution of hedges and boosters across the rhetorical structure of research articles in the $A L$ and $D I$ sub-corpora is presented (in raw numbers) in Table 2 and Table 3 . As shown in Table 2, these interpersonal metadiscourse devices occur systematically in all structural parts of all $A L$ research articles, although their frequency of occurrence varies (hedges range from 45 to 129 , boosters from 14 to 41 ); the only exception are abstracts, where boosters occur in 10 out of 12 texts, while only four abstracts comprise hedges. In the $D I$ sub-corpus (Table 3 ), there is also variation in the presence of the two interpersonal strategies across the research articles (hedges range from 5 to 58 , boosters from 1 to 24 ). In addition to the overall 
lower rate of hedges and boosters in the $D I$ sub-corpus, these interpersonal devices do not occur at all in the Introduction and Method sections of two research articles and in eight abstracts.

Table 2 - Distribution of hedges and boosters in the AL sub-corpus

\begin{tabular}{|c|c|c|c|c|c|c|c|c|c|c|c|c|}
\hline \multirow{2}{*}{$A L$ corpus } & \multicolumn{2}{|c|}{ Abstract } & \multicolumn{2}{|c|}{ Introduction } & \multicolumn{2}{|c|}{ Method } & \multicolumn{2}{|c|}{ Results } & \multicolumn{2}{|c|}{ Discussion } & \multicolumn{2}{|c|}{ Total } \\
\hline & $\mathrm{H}$ & B & $\mathrm{H}$ & B & $\mathrm{H}$ & B & $\mathrm{H}$ & В & $\mathrm{H}$ & B & $\mathrm{H}$ & B \\
\hline $\mathrm{RA}_{1}$ & 1 & 2 & 22 & 7 & 28 & 2 & 5 & 4 & 47 & 6 & 103 & 21 \\
\hline $\mathrm{RA}_{2}$ & 3 & o & 22 & 9 & 15 & 4 & 17 & 8 & 23 & 8 & 83 & 29 \\
\hline $\mathrm{RA}_{3}$ & 2 & o & 21 & 6 & 17 & 1 & $4^{2}$ & 11 & 8 & 8 & 90 & 26 \\
\hline RA 4 & 1 & o & 8 & 5 & 6 & 3 & 41 & 11 & 26 & 3 & 82 & 22 \\
\hline $\mathrm{RA}_{5}$ & 2 & o & 6 & 2 & 7 & 9 & 16 & 15 & 14 & 15 & 45 & 41 \\
\hline RA 6 & 2 & o & 12 & 2 & 26 & 11 & 29 & 8 & 12 & 6 & 81 & 27 \\
\hline $\mathrm{RA}_{7}$ & 5 & o & 21 & 2 & 28 & 6 & 41 & 10 & 34 & 18 & 129 & $3^{6}$ \\
\hline RA 8 & 2 & 2 & 13 & 2 & 2 & 1 & 31 & 7 & 16 & 2 & 64 & 14 \\
\hline RA 9 & o & o & 4 & 1 & 20 & 8 & 33 & 5 & 11 & 4 & 68 & 18 \\
\hline RA 10 & o & o & 27 & 5 & 16 & 5 & 44 & 17 & 15 & 6 & 102 & 33 \\
\hline RA 11 & 1 & 3 & 14 & 8 & 18 & 6 & 35 & 8 & 9 & 8 & 77 & 33 \\
\hline RA 12 & 1 & 1 & 17 & 9 & 1 & o & 40 & 7 & $4^{6}$ & 10 & 105 & 27 \\
\hline Total & 20 & 8 & 187 & $5^{8}$ & 187 & $5^{6}$ & 374 & 111 & 261 & 94 & 1029 & 327 \\
\hline
\end{tabular}

Table 3 - Distribution of hedges and boosters in the DI sub-corpus

\begin{tabular}{|c|c|c|c|c|c|c|c|c|c|c|c|c|}
\hline \multirow{2}{*}{$D I$ corpus } & \multicolumn{2}{|c|}{ Abstract } & \multicolumn{2}{|c|}{ Introduction } & \multicolumn{2}{|c|}{ Method } & \multicolumn{2}{|c|}{ Results } & \multicolumn{2}{|c|}{ Discussion } & \multicolumn{2}{|c|}{ Total } \\
\hline & $\mathrm{H}$ & B & $\mathrm{H}$ & B & $\mathrm{H}$ & B & $\mathrm{H}$ & B & $\mathrm{H}$ & B & $\mathrm{H}$ & B \\
\hline RA 1 & o & o & 5 & 5 & 4 & 6 & 8 & 5 & 10 & 1 & 27 & 17 \\
\hline RA 2 & o & o & 1 & 1 & 9 & 7 & 17 & 7 & 2 & 9 & 29 & 24 \\
\hline $\mathrm{RA}_{3}$ & o & o & 1 & 4 & 2 & 2 & 2 & 1 & 4 & 3 & 9 & 10 \\
\hline RA 4 & o & 2 & o & o & o & o & 9 & 3 & 4 & 1 & 13 & 6 \\
\hline RA 5 & 2 & 1 & 12 & 8 & 16 & o & 18 & 8 & 10 & 5 & $5^{8}$ & 22 \\
\hline RA 6 & o & o & 2 & 1 & o & 1 & 20 & 6 & o & 2 & 22 & 10 \\
\hline $\mathrm{RA}_{7}$ & o & o & 1 & 1 & 7 & 2 & 6 & 5 & 1 & 3 & 15 & 11 \\
\hline
\end{tabular}


OLGA DONTCHEVA-NAVRATILOVA

\begin{tabular}{|c|c|c|c|c|c|c|c|c|c|c|c|c|}
\hline RA 8 & o & o & o & o & o & o & 1 & 1 & 4 & o & 5 & 1 \\
\hline RA 9 & 1 & 2 & o & 1 & 6 & 1 & 21 & 9 & 9 & 4 & $3^{6}$ & 17 \\
\hline RA 10 & o & o & 1 & 1 & 2 & 2 & 1 & 5 & o & 2 & 5 & 10 \\
\hline RA 11 & o & o & o & 3 & 4 & 2 & 1 & o & 8 & 1 & 13 & 6 \\
\hline RA 12 & 2 & 1 & 8 & 5 & 6 & 3 & 2 & 2 & 9 & 3 & 27 & 14 \\
\hline Total & 4 & 6 & 32 & 30 & $5^{6}$ & 26 & 106 & $5^{2}$ & 61 & 34 & 260 & 148 \\
\hline
\end{tabular}

As Table 4 and Figure 2 indicate, the distribution of hedges and boosters across the rhetorical structure of research articles in the $A L$ and $D I$ sub-corpora shows the same overall tendency - hedges and boosters peak in the Results section and to a lesser extent in the Discussion section. In both sub-corpora the rate of these interpersonal devices is the lowest in abstracts. However, the two sub-corpora differ in the relative prominence given to these interpersonal discourse strategies in the individual rhetorical sections of research articles.

Table 4 - Distribution of hedges and boosters across the rhetorical structure of the $D I$ and $A L$ sub-corpora

\begin{tabular}{|l|l|l|l|l|l|l|l|l|l|l|l|l|l|}
\hline \multirow{2}{*}{ Corpus } & \multicolumn{2}{|l|}{ Abstract } & \multicolumn{2}{l|}{ Introduction } & \multicolumn{2}{l|}{ Method } & \multicolumn{2}{l|}{ Results } & \multicolumn{2}{l|}{ Discussion } & \multicolumn{2}{l|}{ Total } \\
\cline { 2 - 15 } & $\mathrm{H}$ & $\mathrm{B}$ & $\mathrm{H}$ & $\mathrm{B}$ & $\mathrm{H}$ & $\mathrm{B}$ & $\mathrm{H}$ & $\mathrm{B}$ & $\mathrm{H}$ & $\mathrm{B}$ & $\mathrm{H}$ & $\mathrm{B}$ \\
\hline DI & & & & & & & & & & & & \\
\hline $\begin{array}{l}\text { Raw } \\
\text { No }\end{array}$ & 4 & 6 & 32 & 30 & 56 & 26 & 106 & 52 & 61 & 34 & 260 & 148 \\
\hline N. rate & 0.08 & 0.11 & 0.61 & 0.57 & 1.08 & 0.50 & 2.04 & 1.00 & 1.17 & 0.65 & 5.00 & 2.84 \\
\hline $\begin{array}{l}\text { Per } \\
\text { cent }\end{array}$ & 1.53 & 4.05 & 12.32 & 20.27 & 21.53 & 17.56 & 40.76 & 35.13 & 23.4 & 22.97 & $63.7 \%$ & $36.3 \%$ \\
\hline AL & & & & & & & & & & & & \\
\hline $\begin{array}{l}\text { Raw } \\
\text { No }\end{array}$ & 20 & 8 & 187 & 58 & 187 & 56 & 374 & 111 & 261 & 94 & 1029 & 327 \\
\hline N. rate & 0.22 & 0.09 & 2.09 & 0.64 & 2.09 & 0.62 & 4.17 & 1.24 & 2.91 & 1.06 & 11.49 & 3.65 \\
\hline $\begin{array}{l}\text { Per } \\
\text { cent }\end{array}$ & 1.94 & 2.44 & 18.07 & 17.73 & 18.07 & 17.12 & 36.35 & 33.95 & 25.37 & 28.74 & $80 \%$ & $20 \%$ \\
\hline
\end{tabular}


Figure 2 - Distribution of hedges and boosters across the rhetorical structure of the $D I$ and $A L$ sub-corpora (normalized rate per 1,000 words)

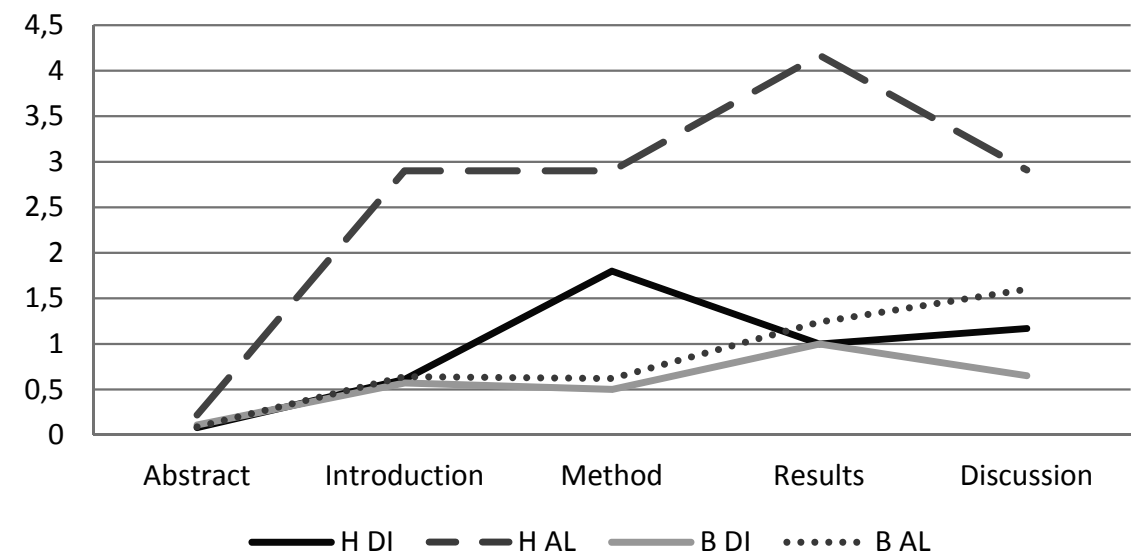

The different treatment of hedging and boosting in abstracts as compared to the full-length texts of research articles in the $D I$ and $A L$ sub-corpora is in conformity with the view that the abstract is a separate genre. Abstracts not only summarize the associated research article but also strive to persuade the reader to engage with the whole study (cf. Hyland 2000, Yakhontova 2002). This promotional function of abstracts tends to favour the use of boosting rather than hedging, which is more prominent in the full-length text of research articles. However, as Gillaerts \& Van de Velde's (2010: 136) findings suggest, in recent years abstracts have undergone a generic shift from an embedded genre (Bhatia 2004) to a stand-alone genre. As a result, recent abstracts show a decrease in interactional metadiscourse and an increase in factual discourse material aimed at facilitating a quick exchange of research results; thus their primary function now seems to be informative rather than promotional. The results of my investigation seem to support this tendency, as the rate of hedging and boosting in abstracts in both sub-corpora is considerably lower than in the full-length text of research articles. In both sub-corpora interactional metadiscourse in abstracts is associated primarily with the presentation of research results: the use of boosters enhances the reliability of new knowledge, as shown in (1) and (2), while the use of hedges indicates the adoption of a more tentative stance (3). 
(1) We demonstrate that this inconsistency has resulted from inadequate control, in previous studies, of certain important variables including the basis of norm comparisons, and we present a principled method for collecting, scoring, and analysing association responses, to address these issues. (AL11, Abstract)

(2) The study demonstrates the possibilities of using parallel English-Czech and Czech-English corpora to reveal quantitative differences in the ways the chosen English DMs co-occur with expressions of agreement and disagreement (narrowed in this analysis to yes and no) and gives evidence of the qualitative preferences of Czech equivalents along the syntagmatic axis. (DI11, Abstract)

(3) The paper argues that working with very explicit and oversimplified models of lexicons might sometimes have advantages over working with more realistic but vague models, whose detailed workings are underspecified. (AL7, Abstract)

As regards the full-length text of research articles, in the $A L$ sub-corpus there are no significant differences in the proportional distribution of hedges and boosters in the Introduction (18.07\% of all hedges vs. $17.73 \%$ of all boosters) and Method (18.07\% of all hedges vs. $17.12 \%$ of all boosters) sections. However, the rate of hedges exceeds considerably that of boosters (2.09 vs. 0.64 and 2.09 vs. 0.62 per 1,00o words respectively). This indicates that Anglophone linguists tend to present their reasoning as plausible rather than certain (4), thus opening a dialogic space for readers to dispute their opinions or procedural decisions (5). This approach, most typical of Introductions, also enables the authors to make their discourse heteroglossic, i.e., inclusive of multiple views, positions and sources, which may be instrumental for claiming credibility and enhancing the persuasive force of the argumentation (Gray \& Biber 2012).

(4) Probably the most important source for explanatory stories of this kind-and as such, an important reference-point for the new biologism - is evolutionary psychology (hereafter 'EP'). (AL1O, Introduction)

(5) Although it might be argued that our sample is not representative of the genre, in so far as the corpus is made up of the writings of one individual, we would argue that what it loses in breadth, it gains in depth (i.e. in the insights of the producer of the texts in question). We acknowledge, however, that no generalizations are possible from the results of our findings. Rather, we would claim that our paper offers a qualitative study of how one editor constructs his editorial letters. (AL3, Introduction) 
The relatively minor differences in the Results ( $36.35 \%$ of all hedges vs. $33.95 \%$ of all boosters) and the Discussion (25.37\% of all hedges vs. $28.74 \%$ of all boosters) sections indicate that in accordance with the interpretative nature of the discipline Anglophone linguists tend to show greater tentativeness when interpreting results, thus anticipating criticism and alternative views (6), but adopt a more assertive stance when they discuss their findings, compare them to previous research and strive to highlight their contribution to an extension of disciplinary knowledge (7).

(6) To summarize, the first stage of analysis suggests that DMs, though they may appear as small words in conversations, can fulfil diverse discourse functions in the four multi-categorial categories, such as intimacy signals, boundary markers, connectors, confirmation seekers turn takers, topic switchers, hesitation markers, repair markers, and attitude markers. (AL5, Results)

(7) In contrast, in the present study we found that classroom teaching mixed 'oral' and 'literate' characteristics in the use of lexical bundles, actually going beyond the expected 'targets' in its patterns of use. (AL5, Conclusion)

Variation in the proportional distribution of hedges and boosters across the rhetorical structure of research articles in the $D I$ sub-corpus is more significant. In contrast to the $A L$ sub-corpus, the most prominent divergences are in the Introduction (12.32\% of all hedges vs. $20.27 \%$ of all boosters) and Method (21.53\% of all hedges vs. $17.56 \%$ of all boosters) sections; the difference is smaller in the Results section (40.76\% of all hedges vs. $35.13 \%$ of all boosters), while there is approximately the same proportion of hedges and boosters in the Discussion section (23.4\% of all hedges vs. $22.97 \%$ of all boosters).

The lower incidence of hedges in the Introduction section suggests that Czech linguists use less qualified language and thus sound more authoritative and confident when asserting the centrality of the topic under investigation and relating their work to previous research (8); this is not surprising, as the Czech linguistics community shows a marked preference towards adherence to a shared methodological framework and field of research. At the same time divergence from established procedures and views (9) seems to be perceived as face-threatening which may explain the higher incidence of hedges, especially in the Method section.

(8) Since the pioneering work of Jan Firbas into the theory of functional sentence perspective, the interpretative analysis of the clause has been the 
cornerstone of FSP. Indeed, it is the FSP analysis of a basic distributional field (clause) that is the basis of the functional interpretation. (DI1, Introduction)

(9) In our view, it is not possible to compare the 'communication' that takes place in newspaper discourse between the 'writer' and 'reader', as we would analyze it in face-to-face conversation because with newspaper discourse the negotiation of meaning is excluded. (DI5, Method)

As with the $A L$ sub-corpus, in the $D I$ sub-corpus hedging is most prominent in the Results section, where authors adopt a tentative stance and express cautious commitment to claims (10). The lower rate of boosters used by Czech linguists in the Discussion section indicates a lesser degree of confidence in promoting findings and claiming contribution to disciplinary knowledge, while the occurrence of hedges is typically related to indication of limitations of the study (11).

(10) This shift of functions may be put down to the appearance of additional information, the emotiveness, which is irretrievable from the immediately relevant context (cf. Chamonikolasová 2007: 35-37). Even though none of the native speakers opted spontaneously for this particular prosodic realization it could not be dismissed as inappropriate and therefore it was put in the category of "other possibilities". Nonetheless, one could argue that emotiveness was not the underlying motive for all 30 per cent of the Czech speakers ... (DI6, Results)

(11) All this makes the findings somerohat inconclusive - they suggest tendencies rather than taboos - and the well worn but truthful statement that more data and research are needed applies even here. (DI11, Conclusion)

As to the choice of interpersonal metadiscourse devices, Table 4 shows the most frequent realizations of hedges and boosters in the two sub-corpora. The results generally converge with Hyland's (1998a) findings indicating that the most frequent devices used to modify statements are a relatively small number of modal and epistemic verbs.

There are, however, differences in the choice of the most frequent realizations of hedges and boosters in the two sub-corpora. While in the $A L$ corpus the most prominent hedges are modal verbs (may, would, might and could) and epistemic verbs (suggest, indicate, argue, tend and seem), in the DI sub-corpus the rate of might is insignificant, but there is a marked presence of approximators (often, frequently and usually). From a functional point of 
view, this means that Anglophone linguists use primarily writer- and readeroriented hedges which have a protective and reader-involvement function respectively, while Czech linguists show greater concern for the precision and accuracy of propositional content expressed by content-oriented hedges. In this case, variation seems to be motivated by the tendency towards dialogism and marked reader awareness typical of Anglophone academic discourse, as opposed to the focus on conceptual clarity emblematic of Czech academic discourse. The difference in the realizations of boosters concerns primarily the epistemic mental verbs think and believe, which are prominent in the $A L$ sub-corpus but scarcely occur in the $D I$ sub-corpus. This low occurrence of think and believe may be explained by the fact that they tend to occur in selfmention structures, which are not very frequent in Czech linguists' English medium discourse (Dontcheva-Navratilova 2013a).

Table 4 - Most frequent hedges and boosters in the DI and AL sub-corpora (listed in descending order of frequency)

\begin{tabular}{|l|l|l|l|}
\hline \multicolumn{2}{|l|}{ AL corpus } & DI corpus \\
\hline Hedges & Boosters & Hedges & Boosters \\
\hline may & show & may & found \\
\hline would & found & would & show \\
\hline might & will & possible (possibly) & will \\
\hline suggest & clear(ly) & often & fact \\
\hline indicate & think & could & clear(ly) \\
\hline could & know & seem & demonstrate \\
\hline possible (possibly) & fact & frequently & always \\
\hline argue & believe & suggest & obviously \\
\hline tend & actually & tend & know \\
\hline seem & obviously & usually & indeed \\
\hline
\end{tabular}

Overall, the contrastive analysis of the rate, distribution and choice of hedges and boosters in the research articles by Czech and Anglophone linguists has revealed that there are both similarities and differences in the way they employ these interactional metadiscourse devices to persuade the intended readership to accept their views and claims. The similarities concern the 
distribution of hedges and boosters across the rhetorical structure of research articles and to a large extent the choice of the most frequent realizations of hedges and boosters. The most significant difference between the $A L$ and the $D I$ sub-corpora is in the rate of occurrence of hedges and boosters, which is considerably lower in the research articles by Czech linguists. The reasons for this seem to stem from culturally driven rhetorical preferences, the size of the two linguistics communities and the intended readership of the two journals, and the constraint of using English as an additional language.

\section{Conclusion}

Undertaken from a cross-cultural perspective, this study intended to identify similarities and differences in the use of hedges and boosters in a corpus of research articles by Anglophone and Czech linguists in order to explore how these interpersonal metadiscourse devices partake in the construal of persuasion in academic discourse. The findings of the cross-cultural analysis suggest that while similarities in the distribution and choice of hedging and boosting devices seem to be discipline- and genre-driven, the existing variation is likely to reflect differences in the linguacultural and epistemological tradition of the Anglophone and Czech linguistics communities, which favour different rhetorical strategies when approaching writer-reader interaction, and the constraints of using English as a lingua franca of globalized academia. The more prominent use of hedging and boosting in research articles by Anglophone linguists seems to reflect the large size and competitive character of the heterogeneous international discourse community, where authorial credibility is enhanced by interacting with different voices and views. By contrast, the lower rate of hedges and boosters and the prominence of contentoriented hedges in research articles by Czech linguists suggest that the tendency towards symbiosis in the small Czech linguistics community is still significant and tends to affect their rhetorical choices even when they write Englishmedium texts potentially addressed to an international audience. However, the relatively high proportion of boosters in the DI sub-corpus indicates a rise of competitiveness among the members of the Czech linguistics community which seems to reflect the globalization and marketization of academia.

The findings of this study confirm the importance of cross-cultural studies in interpersonal metadiscourse as a key aspect of academic persuasion. However, a wider-scope synchronic and diachronic analysis is necessary to reveal the 
gradual changes in the discourse practices of the Anglophone and Czech linguistics communities. Further research should also show the extent to which texts by non-Anglophone authors conform to dominant discourse conventions or give rise to "interdiscursive hybridity" (Mauranen et al. 2010), thus reflecting intercultural tension (Gotti 2012).

\section{Works Cited}

Abdollahzadeh, Esmaeel. "Poring over the findings: Interpersonal authorial engagement in applied linguistics papers." Journal of Pragmatics 43 (2011): 288-297. Print.

Bhatia, Vijay K. Worlds of Written Discourse. A Genre-Based View. New York: Continuum, 2004. Print.

Brown, Peneloppe and Stephen Levinson. Politeness. Some Universals in Language Usage. Cambridge: Cambridge University Press, 1987. Print.

Clemen, Gudrun. "The concept of hedging: Origins, approaches and definitions." Eds. Raija Markkanen and Hartmut Schröder. Hedging and Discourse. Approaches to the Analysis of a Pragmatic Phenomenon in Academic Texts. New York: Walter de Gruyter, 1997. 235-248. Print.

Dontcheva-Navratilova, Olga. "Authorial presence in academic discourse: Functions of author-reference pronouns." Linguistica Pragensia 23/1 (2013a), 9-30. Print.

---. "The Changing face of Czech academic discourse." Ed. Karen Bennett. The Semiperiphery of Academic Writing. Basingstoke: Palgrave Macmillan, 2013b. 39-61. Print.

--.. "Cross-cultural variation in citation practices: A comparative analysis of citations in Czech English-medium and international English-medium linguistics journals." Eds. Ramón Plo Alastrué and Carmen Pérez-Llantada. English as a Scientific and Research Language. Berlin/Boston: Mouton de Gruyter, 2015. 185-205. Print.

Fløttum, Kjersti. "Personal English, indefinite French and plural Norwegian scientific authors? Pronominal author manifestation in research articles." Norsk Linguistisk Tidsskrift 21/1 (2003), 21-55. Print.

Gillaerts, Paul and Freek Van de Velde. "Interactional metadiscourse in research article abstracts." Journal of English for Academic purposes 9 (2010), 128-139. Print.

Gotti, Maurizio. "Cross-cultural aspects of academic discourse." Brno Studies in English 38 (2), (2012), 59-78. Print. 
Gray, Bethany and Douglas Biber. Current conceptions of stance. Eds. Hyland, Ken and Carmen Sancho Guinda. Stance and Voice in Written Academic Genres. Basingstoke: Palgrave Macmillan, 2012. 15-33. Print.

Hewings, Ann, Theresa Lillis and Dimitra Vladimirou. "Who's citing whose writings? A corpus based study of citations as interpersonal resource in English medium national and English medium international journals." Journal of English for Academic Purposes 9 (2010), 102-115. Print.

Holmes, Janet. "Hedges and boosters in women's and men's speech." Language \& Communication 10 (1990), 185-205. Print.

--. Men, women and politeness. New York: Longman, 1995. Print.

---. "Modifying illocutionary force." Journal of Pragmatics 8 (1984), 345-365. Print.

$\mathrm{Hu}$, Guangwei and Feng Cao. "Hedging and boosting in abstracts of applied linguistics articles: A comparative study of English- and Chinese-medium journals." Fournal of Pragmatics 43 (2011), 2795-2809. Print.

Hyland, Ken. "Boosting, hedging and the negotiation of academic knowledge." Text 18 (1998a), 349-382. Print.

---. Disciplinary Discourses: Social Interactions in Academic Writing. London: Longman, 2000. Print.

---. Hedging in Scientific Research Articles. John Benjamins, Amsterdam, 1998b. Print.

--. Metadiscourse: Exploring writing in interaction. London: Continuum, 2005. Print.

--. "Nurturing hedges in the ESP curriculum." System 24/4 (1996), 477-490. Print.

--. "Persuasion and context: The pragmatics of metadiscourse." Fournal of Pragmatics 30 (1998c), 437-455. Print.

--. "Persuasion, interaction and the construction of knowledge: Presenting self and others in research writing." IfES 2/8 (2008), 1-23. Print.

Hyland, Ken and John Milton. "Qualification and certainty in L1 and L2 students' writing." Journal of Second Language Writing 6 (1997), 183-205. Print.

Hyland, Ken and Polly Tse. "Metadiscourse in academic writing: A reappraisal." Applied Linguistics 25 (2004), 156-177. Print.

Ivanič, Roz. Writing and Identity: The Discoursal Construction of Identity in Academic Writing. Amsterdam: John Benjamins, 1998. Print.

Martín-Martín, Pedro. "The mitigation of scientific claims in research papers: A comparative study." IfES 8/2 (2008), 133-152. Print. 
Mauranen, Anna. "Contrastive ESP Rhetoric: Metatext in Finnish-English Economics texts." English for Specific Purposes 12 (1993), 3-22. Print.

---. Hedging in language reviser's hands. Eds. Raija Markkanen and Hartmut Schröder. Hedging and Discourse. Approaches to the Analysis of a Pragmatic Phenomenon in Academic Texts. New York: Walter de Gruyter, 1997. 115-133. Print.

Mauranen, Anna, Carmen Pérez-Llantada and John Swales. "Academic Englishes: A standardized knowledge?" Ed. Kirkpatrick, Andy. The Routledge Handbook of World Englishes. London: Routledge, 2010. 634-652. Print.

Molino, Alessandra. "Personal and impersonal authorial references: A contrastive study of English and Italian linguistics research articles." fournal of English for Academic Purposes 9/2 (2010), 86-101. Print.

Mur-Dueňas, Pilar. "I/we focus on...: A cross-cultural analysis of self-mentions in business management research articles." Fournal of English for Academic Purposes 6 (2007), 143-162. Print.

---. "Citation in business management research articles." Eds. Suomela-Salmi Eija and Fred Dervin. Cross-cultural linguistic and cross-cultural perspectives on academic discourse. Amsterdam \& New York: John Benjamins, 2009. 4o-6o. Print.

Povolná, Renata. "Cross-cultural variation in the degree of dialogicality in research articles: On some text-organizing devices." Dontcheva-Navratilova, Olga, Renata Jančaříková, Gabriela Miššíková and Renata Povolná. Coherence and Cohesion in English Discourse. Brno: Masaryk University, 2012. 29-58. Print.

---. "On cross-cultural variation in the use of conjuncts in research articles by Czech and native speakers of English of English: Can conjuncts contribute to the interactive and dialogic character of academic texts?" Eds. Ramón Plo Alastrué and Carmen Pérez-Llantada. English as a Scientific and Research Language. Berlin/Boston: Mouton de Gruyter, 2015. 115-140. Print.

Prince, Ellen R., Joel Frader and Charles Bosk. "On hedging in physicianphysician discourse." Ed. Robert J. Di Pietro Linguistics and the professions. Proceedings of the second annual Delaware symposium on language studies. Norwood, NJ: Ablex, 1982. 83-97. Print.

Salager-Meyer, Françoise. "Hedges and textual communicative function in medical English written discourse." English for Specific Purposes 3 (1994), 49-170. Print.

Samaie, Mahmoud, Fereshteh Khosravian and Mahnaz Boghayeri. "The frequency and types of hedges in research article Introductions by Persian 
and English native authors." Procedia - Social and Behavioral Sciences 98 (2014), 1678-1685. Print.

Takimoto, Masahiro. "Assertions and lexical invisibility in EFL learners' academic essays." Fournal of Pragmatics 89 (2015), 85-99. Print.

Vassileva, Irena. Commitment and detachment in English and Bulgarian academic writing. English for Specic Purposes 20 (2001), 83-102. Print.

---. "Who am I/who are we in academic writing?" International fournal of Applied Linguistics 8/2 (1998), 163-192. Print.

---. Who is the author? A contrastive analysis of authorial presence in English, German, French, Russian and Bulgarian academic discourse. Sankt Augustin: Asgard Verlag, 200o. Print.

Vázquez, Ignacio and Diana Giner. "Beyond Mood and Modality: Epistemic Modality Markers as Hedges in Research Articles. A Cross-Disciplinary Study." Revista Alicantina de Estudios Ingleses 21 (2008), 171-19o. Print.

---. "Writing with Conviction: The Use of Boosters in Modelling Persuasion in Academic Discourses. A Cross-Disciplinary Study." Revista Alicantina de Estudios Ingleses 22 (2008), 219-237. Print.

Yakhontova, Tatyana. "Cultural and disciplinary variation in academic discourse: The issue of influencing factors." Journal of English for Academic Purposes 5 (2006), 153-167. Print.

-.-. "Selling' or 'telling'? The issue of cultural variation in research genres." Ed. John Flowerdew. Academic discourse. Harlow: Longman, 2002. 216-232. Print. Yang, Yingli. "Exploring linguistic and cultural variations in the use of hedges in English and Chinese scientific discourse." Journal of Pragmatics 50 (2013), 23-36. Print.

OLGA DONTCHEVA-NAVRATILOVA is Associate Professor of English Linguistics at the Faculty of Education, Masaryk University in Brno, Czech Republic. She specializes in discourse analysis, genre analysis, stylistics and pragmatics, with a focus on political and academic discourse. She has published many articles, the books Analysing Genre: The Colony Text of UNESCO Resolutions (2009) and Coherence in Political Speeches (2011) and co-authored the volume Cohesion and Coherence in English Discourse (2012). She is co-editor of Coherence and Cohesion in Spoken and Written Discourse (2009) and Discourse Interpretation: Approaches and Applications (2012) published by Cambridge Scholars Publishing. She is also co-editor of the linguistics journal Discourse and Interaction.

navratilova@ped.muni.cz 